\title{
Optimization of cultivation conditions for biotechnological production of lipid by Rhodotorula kratochvilovae (syn, Rhodosporidium kratochvilovae) SY89 for biodiesel preparation
}

\author{
Tamene Milkessa Jiru ${ }^{1} \cdot$ Marizeth Groenewald ${ }^{2}$ Carolina Pohl ${ }^{3} \cdot$ Laurinda Steyn $^{3}$. \\ Nicholas Kiggundu ${ }^{4}$. Dawit Abate ${ }^{1}$
}

Received: 31 October 2016/Accepted: 6 February 2017/Published online: 8 June 2017

(c) Springer-Verlag Berlin Heidelberg 2017

\begin{abstract}
Rhodotorula kratochvilovae (syn, Rhodosporidium kratochvilovae) SY89, an oleaginous yeast, isolated from Ethiopian soil, was grown under nitrogen-limited media. The capacity this with respect to biomass production, lipid yield and lipid content was evaluated. The influence of inoculum size, carbon sources, variations in glucose concentration, nitrogen sources, $C / N$ ratio, $\mathrm{pH}$, temperature, agitation, and aeration rate and incubation period were investigated. Inoculum size of $10 \% \mathrm{v} / \mathrm{v}$, glucose as a carbon source at $50 \mathrm{~g} /$ L glucose, $0.50 \mathrm{~g} / \mathrm{L}$ yeast extract and $0.31 \mathrm{~g} / \mathrm{L}\left(\mathrm{NH}_{4}\right)_{2} \mathrm{SO}_{4}, \mathrm{Cl}$ $N$ ratio of $120, \mathrm{pH} 5.5$, incubation temperature of $30^{\circ} \mathrm{C}$,
\end{abstract}

Tamene Milkessa Jiru

tamene.milkessa@aau.edu.et

Marizeth Groenewald

m.groenewald@westerdijkinstitute.nl

Carolina Pohl

PohlCH@ufs.ac.za

Laurinda Steyn

Steynl@ufs.ac.za

Nicholas Kiggundu

kiggundu@caes.mak.ac.ug

Dawit Abate

dawit.abate@aau.edu.et

1 Microbial, Cellular and Molecular Biology Department, College of Natural Science, Addis Ababa University, P.O. Box 1176, Addis Ababa, Ethiopia

2 Westerdijk Fungal Biodiversity Institute, Uppsalalaan 8, P.O. Box 85167, 3508 AD, Utrecht, The Netherlands

3 Department of Microbial, Biochemical and Food Biotechnology, University of the Free State, P.O. Box 339, Bloemfontein, South Africa

4 Department of Agricultural and Biosystems-Engineering, School of Food Technology, Nutrition and Bio-Engineering, Makerere University, P.O. Box 7062, Kampala, Uganda
$225 \mathrm{rpm}, 0.2$ as aeration ratio and $144 \mathrm{~h}$ of incubation were found to be optimum conditions for lipid production. Then the yeast was grown in a batch bioreactor by combining the different optimized parameters together. Under the optimized conditions, the yeast gave maximum biomass $(15.34 \pm 1.47 \mathrm{~g} / \mathrm{L})$, lipid yield $(8.60 \pm 0.81 \mathrm{~g} / \mathrm{L})$ and lipid content $(56.06 \pm 1.70 \%)$. The dominant fatty acids exhibited in order of their relative abundance $(\% \mathrm{w} / \mathrm{w})$, were oleic, palmitic, linoleic, stearic, linolenic and palmitoleic acids. The concentration of saturated and monounsaturated fatty acids adds up $78.63 \pm 2.19 \%$. This suggests that this strain could be used as a good feedstock for biodiesel production.

Keywords Biodiesel - Cultivation conditions · Fatty acid . Oleaginous yeast $\cdot$ Rhodotorula kratochvilovae (syn, Rhodosporidium kratochvilovae)

\section{Introduction}

Microorganisms that are capable of accumulating lipids above 20 up to $70 \%$ of their dry biomass are termed as oleaginous (Ratledge and Wynn 2002). The oil produced can be exploited as alternative sources of oils and fats for human consumption and can also be used as feedstocks for the production of biodiesel ( $\mathrm{Li}$ et al. 2008) and components in paints and coatings, detergents, cleaning products, cosmetics, plastics, rubber, crop protection and intermediate products or synthons (Luque et al. 2010).

Compared to vegetable oils, the production of microbial oil has many advantages which include: high growth rate, short life cycle, less labor requirement, less affection by venue, season and climate, no arable land needed, easier to scale up ( $\mathrm{Li}$ et al. 2008), and ability to use different carbon sources (Economou et al. 2011). 
Basidiomycetous yeasts prevail among oleaginous yeasts. Many basidiomycetous yeasts including Rhodosporidium are now included in other existing or new genera (Wang et al. 2015). Accordingly, Rhodosporidium has been transferred to Rhodotorula and the oleaginous yeast Rhodosporidium kratochvilovae is renamed as Rhodotorula kratochvilovae (Wang et al. 2015).

Oil accumulation by oleaginous microorganisms depends highly on the culturing conditions such as inoculum size, the available carbon and nitrogen source in the growing medium, concentration of both carbon and nitrogen sources, $C / N$ ratio, $\mathrm{pH}$, temperature, culture time and agitation, and aeration rate ( $\mathrm{Li}$ et al. 2008). Optimum initial $C / N$ ratio of greater than 20 is needed for maximum production of lipids by oleaginous microorganisms (Papanikolaou and Aggelis 2011). $C / N$ ratio depends on the nature of the microorganism, the medium composition in which the cultivation is undertaken, and types of carbon and nitrogen sources (Ykema et al. 1986). It is reported that lipid accumulation in oleaginous yeasts occurs when the growth medium is replete in carbon source with one limiting element that is usually nitrogen limitation (Wu et al. 2011).

Inoculum size or inoculation volume as a starter culture in the growing medium plays a key role on yeast single cell oil production. Optimum inoculum size is need for maximum biomass and hence higher lipid production. A low inoculum size could result in long lag phase (Kitcha 2012).

The influence of initial $\mathrm{pH}$ of the culture medium also plays a critical role on lipid synthesis by oleaginous microorganisms. Different optimum $\mathrm{pH}$ values for maximum production of lipids by different oleaginous yeasts were found in previous studies (Tao et al. 2008; Zhu et al. 2008; El-Fadaly et al. 2009; Kraisintu et al. 2010). The optimum $\mathrm{pH}$ for each oleaginous yeast for biomass production and hence single cell oil is also influenced by the different carbon sources available in the growth medium (Angerbauer et al. 2008). A decrease in lipid production was exhibited when the $\mathrm{pH}$ was below 4.0 and above 8.0 (Syed et al. 2006).

Temperature of the culture medium critically influences cellular lipid accumulation by an oleaginous microorganism. Too high or too low temperature affects the cell growth and lipid accumulation (Sha 2013). The composition of the lipid also varies at different temperatures (Saxena et al. 2009).

Culturing time (incubation period) also has an effect on lipid production. Usually lipid content reaches its highest value at stationary phase of microbial growth (Beopoulos et al. 2008). It is recommended that cells should be harvested at early stationary phase to prevent lipid degradation (Beopoulos et al. 2008).
In addition to the above factors, agitation and aeration rates play a significant role on the production of single cell oil by oleaginous microorganisms. These parameters play a pivotal role in aerobic fermentation process and in scaling up of aerobic biosynthesis systems (Bandaiphet and Prasertsan 2006).

It is clear from the previous studies that optimization of cultivation parameters can result in higher lipid production by oleaginous yeasts and fosters their potential for industrial application. Optimization is an essential step for each industrial process because it can result in higher production under economical cost (Enshaeieh et al. 2013).

The objective of this study was to investigate the effect of different parameters on biomass production, lipid yield and lipid content of $R$. kratochvilovae SY89. The parameters tested, included growth on different carbon sources, combining inorganic and organic nitrogen sources, changes in $\mathrm{C} / \mathrm{N}$ ratios and $\mathrm{pH}$, agitation and aeration rates, different incubation temperatures and time of incubation.

\section{Materials and methods}

\section{Sample collection and yeast isolation}

About 200 samples were collected from soil, plant surfaces (leaves, fruits and flowers), dairy products (milk, yogurt and cheese) and traditional oil mill wastes in Ethiopia. Yeast isolation was performed according to the methods of Pan et al. (2009).

\section{Screening for oleaginous yeast and determination of lipid content}

The isolated yeast cultures were screened for their lipid producing abilities by qualitative analysis with the Sudan III staining technique (Thakur et al. 1988) and all yeasts positive for lipid production were further characterized and identified.

Yeast cells which were grown on nitrogen-limited media [70 g/L glucose, $0.3 \mathrm{~g} / \mathrm{L}\left(\mathrm{NH}_{4}\right)_{2} \mathrm{SO}_{4}, 0.3 \mathrm{~g} / \mathrm{L}$ yeast extract, $2.0 \mathrm{~g} / \mathrm{L} \quad \mathrm{KH}_{2} \mathrm{PO}_{4}, 1.5 \mathrm{~g} / \mathrm{L} \quad \mathrm{MgSO}_{4} \cdot 7 \mathrm{H}_{2} \mathrm{O}, 0.25 \mathrm{~g} / \mathrm{L}$ citric acid, $\quad 0.1 \mathrm{~g} / \mathrm{L} \quad \mathrm{CaCl}_{2} \cdot 2 \mathrm{H}_{2} \mathrm{O}, 0.035 \mathrm{~g} / \mathrm{L} \quad \mathrm{FeSO}_{4} \cdot 7 \mathrm{H}_{2} \mathrm{O}$, $0.011 \mathrm{~g} / \mathrm{L} \mathrm{ZnSO}_{4} \cdot 7 \mathrm{H}_{2} \mathrm{O}, 0.007 \mathrm{~g} / \mathrm{L} \mathrm{MnSO}_{4} \cdot \mathrm{H}_{2} \mathrm{O}, 0.002 \mathrm{~g} / \mathrm{L}$ $\mathrm{CoCl} \cdot 6 \mathrm{H}_{2} \mathrm{O}, 0.0013 \mathrm{~g} / \mathrm{L} \mathrm{Na}_{2} \mathrm{MoO}_{4} \cdot 2 \mathrm{H}_{2} \mathrm{O}$, and $0.001 \mathrm{~g} / \mathrm{L}$ $\left.\mathrm{CuSO}_{4} \cdot 5 \mathrm{H}_{2} \mathrm{O}\right]$ were harvested by centrifugation at $5000 \times g$ for $15 \mathrm{~min}$. Biomass (pellet) was harvested and washed twice with distilled water, frozen at $-80{ }^{\circ} \mathrm{C}$ and freeze dried over night to constant weight. The dry weight of oleaginous yeast was determined gravimetrically (Pan et al. 2009).

Lipid extraction was done following the protocol described by Folch et al. (1957), with some modifications. 
Freeze dried biomass was ground with a pestle in a mortar and $1 \mathrm{~g}$ of sample was extracted with $3.75 \mathrm{~mL}$ solvent mixture of chloroform and methanol (2:1) overnight. The solvent mixture was transferred into a clean separating funnel through Whatman No1 filter paper. Then $1.25 \mathrm{~mL}$ of the solvent mixture was added through filter paper into separating funnel. This was followed by washing with $0.75 \mathrm{~mL}$ of distilled water. The solvent/water mixture was left overnight to separate into two clear phases. The bottom phase was collected and the solvents evaporated under vacuum. Diethyl ether was used to transfer the extract into pre-weighed glass vials and the solvent evaporated. The dry lipids were weighed and lipid content was calculated using Eq. 1 .

Single cell oil content $=\frac{\text { Single cell oil weight }(\mathrm{g} / \mathrm{L})}{\text { Cell dry weight }(\mathrm{g} / \mathrm{L})}$

$$
\times 100 \text {. }
$$

\section{Identification of the yeast}

\section{Morphological and physiological tests}

Various morphological and physiological tests were undertaken for identification purposes following the methods of Kurtzman et al. (2011). Morphological characteristics of the cultures such as colony color, size, shape, elevation, texture, and diameter were studied and characterized. Cell shape, dimension and budding features of the strains grown in a liquid Yeast extract-Malt extract (YM) medium (10 g/L glucose, $3 \mathrm{~g} / \mathrm{L}$ yeast extract, $3 \mathrm{~g} / \mathrm{L}$ malt extract and $5 \mathrm{~g} / \mathrm{L}$ peptone) were observed using a microscope. The formation of pseudohyphae, ballistoconidia and ascospore were also tested. The physiological tests that were done include fermentation of carbon sources, assimilation of carbon and nitrogen sources using an auxonographic method, urea hydrolysis, Diazonium blue B color reaction, growth in media of high osmotic pressure, splitting of fat and formation of extracellular amyloid compounds.

\section{Molecular identification of the yeast}

Genomic DNA was extracted from cultures grown on $40 \mathrm{~g} / \mathrm{L}$ glucose, $5 \mathrm{~g} / \mathrm{L}$ peptone, $5 \mathrm{~g} / \mathrm{L}$ yeast autolysate, and $20 \mathrm{~g} / \mathrm{L}$ agar (GPYA) medium for 3 days using the FastDNA kit (BIO101, Carlsbad, CA, USA) with the "FastPrep" Instrument (Q-Biogene). Primers V9G (de Hoog and Gerrits van den Ende 1998) and LR5 (Vilgalys and Hester 1990) were used to amplify the region of the rRNA gene operon that includes the $3^{\prime}$ end of the small- subunit rRNA gene, the ITS regions (ITS 1, ITS 2 and the intervening 5.8S rRNA gene), and the D1/D2 domains of the 26S rRNA gene of the large subunit, as described by Knutsen et al. (2007).

The PCR products were separated by electrophoresis at $80 \mathrm{~V}$ for $40 \mathrm{~min}$ on a $0.8 \%(\mathrm{w} / \mathrm{v})$ agarose gel containing $0.1 \mu \mathrm{g} / \mathrm{mL}$ ethidium bromide in $1 \times$ TAE buffer $(0.4 \mathrm{M}$ Tris, 0.05 M NaAc, and 0.01 M EDTA, pH 7.85) and examined under UV-light. The amplicons were sequenced in both directions using the primers LROR (Vilgalys and Hester 1990) and LR5 for the D1/D2 domain, while the primers V9G and ITS4 (White et al. 1990) were used for the ITS domain. The BigDye Terminator version 3.1 cycle sequencing kit (applied biosystems) was used according to the manufacturer's recommendations and the products were analyzed on an ABI Prism 3730XL DNA Sequencer (Perkin-Elmer). A consensus sequence was computed from the forward and reverse sequences with SeqMan version 8 from the Lasergene package (DNASTAR). All sequences of the studied strains were blasted against sequences in GenBank (http://blast.ncbi.nlm.nih.gov/Blast.cgi) and the CBS yeast database (http://www.cbs.knaw.nl/Collections/) to identify the oleaginous yeasts. Sequences of the D1/D2 domain obtained during this study and related sequences from the GenBank (NCBI) database were aligned and phylogenetic analyses were done using MEGA 7 version (Kumar et al. 2016). The phylogenetic relationship of these yeast strains is displayed in a distance based neighborjoining tree.

\section{Optimization of culture conditions for biomass production and lipid accumulation}

The influence of inoculum size $(5,10,15,20$ and $25 \% \mathrm{v} / \mathrm{v})$ of the yeast, carbon sources (glucose, sucrose, maltose, galactose, xylose and glycerol), glucose concentration (10, $30,50,70$ and $90 \mathrm{~g} / \mathrm{L})$, nitrogen sources $\left[\left(\mathrm{NH}_{4}\right)_{2} \mathrm{SO}_{4}\right.$ and yeast extract, $\mathrm{NH}_{4} \mathrm{Cl}$ and peptone, $\mathrm{NH}_{4} \mathrm{Cl}$ and yeast extract, $\left(\mathrm{NH}_{4}\right)_{2} \mathrm{SO}_{4}$ and peptone, $\left(\mathrm{NH}_{4}\right)_{2} \mathrm{SO}_{4}$ and urea, $\mathrm{NH}_{4} \mathrm{Cl}$ and urea], $C / N$ ratio $(40,60,80,100,120,140$, and 160$), \mathrm{pH}$ (4.0, 4.5, 5.0, 5.5, 6.0, 6.5, and 7.0), temperature (20, 25, 30,35 and $\left.40{ }^{\circ} \mathrm{C}\right)$, agitation speed (100, 125, 150, 175, 200 and $225 \mathrm{rpm})$, aeration ratio $(0.1,0.2,0.3,0.4$ and 0.5$)$ and incubation period $(0,24,48,72,96,120,144$ and $168 \mathrm{~h})$ were tested in a nitrogen-limited media. One parameter was tested at a time. Dry biomass, lipid yield and lipid content were determined. Except for the experiments on aeration ratio, cultures were grown in $250 \mathrm{~mL}$ Erlenmeyer flasks containing $50 \mathrm{~mL}$ media. For determination of $\mathrm{Cl}$ $N$ ratio, total nitrogen content of yeast extract was determined using Kjeldahl apparatus according to the instructions published by Krishna and Ranjhan (1980). 


\section{Bioreactor cultivation SY89 under the optimized conditions}

Bioreactor fermentations were undertaken using glucose as a carbon source in nitrogen-limited medium $[50 \mathrm{~g} / \mathrm{L}$ glucose, $0.31 \mathrm{~g} / \mathrm{L}\left(\mathrm{NH}_{4}\right)_{2} \mathrm{SO}_{4}, 0.50 \mathrm{~g} / \mathrm{L}$ yeast extract, $1.5 \mathrm{~g} / \mathrm{L}$ $\mathrm{MgSO}_{4} \cdot 7 \mathrm{H}_{2} \mathrm{O}, \quad 0.1 \mathrm{~g} / \mathrm{L} \quad \mathrm{CaCl}_{2} \cdot 2 \mathrm{H}_{2} \mathrm{O}, 2.0 \mathrm{~g} / \mathrm{L} \quad \mathrm{KH}_{2} \mathrm{PO}_{4}$, $0.035 \mathrm{~g} / \mathrm{L} \mathrm{FeSO}_{4} \cdot 7 \mathrm{H}_{2} \mathrm{O}, 0.011 \mathrm{~g} / \mathrm{L} \mathrm{ZnSO} \mathrm{Zn}_{4} \cdot 7 \mathrm{H}_{2} \mathrm{O}, 0.007 \mathrm{~g} /$ $\mathrm{L} \mathrm{MnSO}_{4} \cdot \mathrm{H}_{2} \mathrm{O}, 0.002 \mathrm{~g} / \mathrm{L} \mathrm{CoCl} \cdot 6 \mathrm{H}_{2} \mathrm{O}, 0.0013 \mathrm{~g} / \mathrm{L} \mathrm{Na} \mathrm{Na}_{2}$ $\mathrm{MoO}_{4} \cdot 2 \mathrm{H}_{2} \mathrm{O}$ and $\left.0.0001 \mathrm{~g} / \mathrm{L} \mathrm{CuSO}_{4} \cdot 5 \mathrm{H}_{2} \mathrm{O}\right]$. The fermentation medium was inoculated with $10 \%(\mathrm{v} / \mathrm{v})$ of the liquid seed culture and then cultivated in a FerMac320, 0.8 L stirred-tank bioreactor. Fermentations were performed under the optimized conditions: work volume: $600 \mathrm{~mL}$, stirring rate: $500 \mathrm{rpm}$, culture temperature, $30{ }^{\circ} \mathrm{C}$, initial $\mathrm{pH}, 5.5$, aeration rate: $1.25 \mathrm{vvm}$ culture time, $144 \mathrm{~h}$.

\section{Analysis of fatty acids profiles using gas chromatography}

To determine the fatty acid composition of the lipids, the extracted lipids were transferred to GC vials, dissolved in chloroform and methylated with trimethylsulphonium hydroxide (TMSOH) (Butte 1983). The vials were then sealed and vortexed for approximately $5 \mathrm{~s}$. Fatty acid methyl esters were subsequently analyzed on a Shimadzu GC-2010 auto sampler gas chromatograph with a flame ionization detector. An injection volume of $0.5 \mu \mathrm{L}$ of sample was added into a SGE-BPX-70 column (length of $50 \mathrm{~m}$ and inner diameter of $0.22 \mathrm{~mm}$ ). The injection port had a temperature of $250{ }^{\circ} \mathrm{C}$ and a split ratio of $1: 10$. The column temperature was $200{ }^{\circ} \mathrm{C}$. Hydrogen gas was used as a carrier gas at a flow rate of $40 \mathrm{~mL} / \mathrm{min}$. The total program time was 4.50 min per sample with a column flow rate of $1.37 \mathrm{~mL} / \mathrm{min}$. Peaks were identified by reference to authentic standards.

\section{Statistical analysis}

One-way ANOVA was performed to calculate significant differences in treatment means. SPSS version 20.0 software was used for interpretation of the data. Mean separations were performed by Tukey post hoc tests. A $p$ value $<0.05$ was considered significant. All experiments were done in triplicate.

\section{Results and discussion}

\section{Screening potential oleaginous yeast}

After screening using Sudan III stain and determination of oil content of 340 yeast strains isolated from the soil, plant surfaces (leaves, fruits and flowers), dairy products (milk, yogurt and cheese) and wastes from traditional oil milling houses, it was found that the yeast strain SY89, which was isolated from soil contained high oil content $(39.33 \pm 0.57 \%$ w/w). For details Jiru et al. (2016) can be referred. Therefore, the yeast strain SY89 was used in the subsequent analyses.

\section{Identification of yeast strain}

Based on colony and cell morphology of the yeast strain (Fig. 1), it was suggested that SY89 belongs to the genus Rhodosporidium (now Rhodotorula). Physiological tests supported this placement into this genus. The sequence of the D1/D2 domain and ITS region of the 26S rRNA gene was obtained and compared to sequences deposited in GenBank (NCBI) (http://blast.ncbi.nlm.nih.gov/Blast.cgi) and the CBS database (http://www.cbs.knaw.nl/Collections/). The sequence analysis results of SY89 (776 nucleotides, Genbank accession number KX525703) revealed that the amplified sequences were $100 \%$ identical to those corresponding to $R$. kratochvilovae CBS 7436 and $R$. kratochvilovae CECT 11956, while 99\% similarity was exhibited by this yeast strain with $R$. kratochvilovae PYCC4778. So the SY89 was identified as R. kratochvilo$v a e$. The phylogenetic placement of this strain in relation to closely related species, based on the D1/D2 sequence is presented in Fig. 2. The tree obtained by analyzing ITS domain is not shown here since the same relationship among species was obtained.

\section{Effect of various parameters on biomass production and lipid yield}

\section{Effect of inoculum size}

In the present study, the effect of inoculum size on biomass production, lipid yield and cellular lipid content by SY89 were tested using nitrogen-limited media. Maximum dry biomass $(14.28 \pm 0.73 \mathrm{~g} / \mathrm{L})$, lipid yield $(5.32 \pm 0.27 \mathrm{~g} / \mathrm{L})$ and cellular lipid content $(37.25 \pm 0.75 \%)$ were observed at inoculum size of $10 \% \mathrm{v} / \mathrm{v}$, while lowest biomass $(11.52 \pm 0.50 \mathrm{~g} / \mathrm{L})$ was achieved at inoculum size of $5 \%$ v/v (Fig. 3). On the other hand, this yeast strain gave lowest lipid yield $(3.32 \pm 0.39 \mathrm{~g} / \mathrm{L})$ and lipid content $(26.67 \pm 0.85 \%)$ at inoculum size of $25 \% \mathrm{v} / \mathrm{v}$. Based on this an inoculum size of $10 \% \mathrm{v} / \mathrm{v}$ was selected as the optimum inoculum size for SY89.

Size/volume of inoculum as a starter culture in the culture medium plays a crucial role on yeast single cell oil production. Inoculum size of $10 \% \mathrm{v} / \mathrm{v}$ was also the optimum for higher biomass and lipid yield as well as lipid content by Phenoliferia glacialis (syn, Rhodotorula glacialis) DBVPG4875 (Amaretti et al. 2010). Inoculum size 

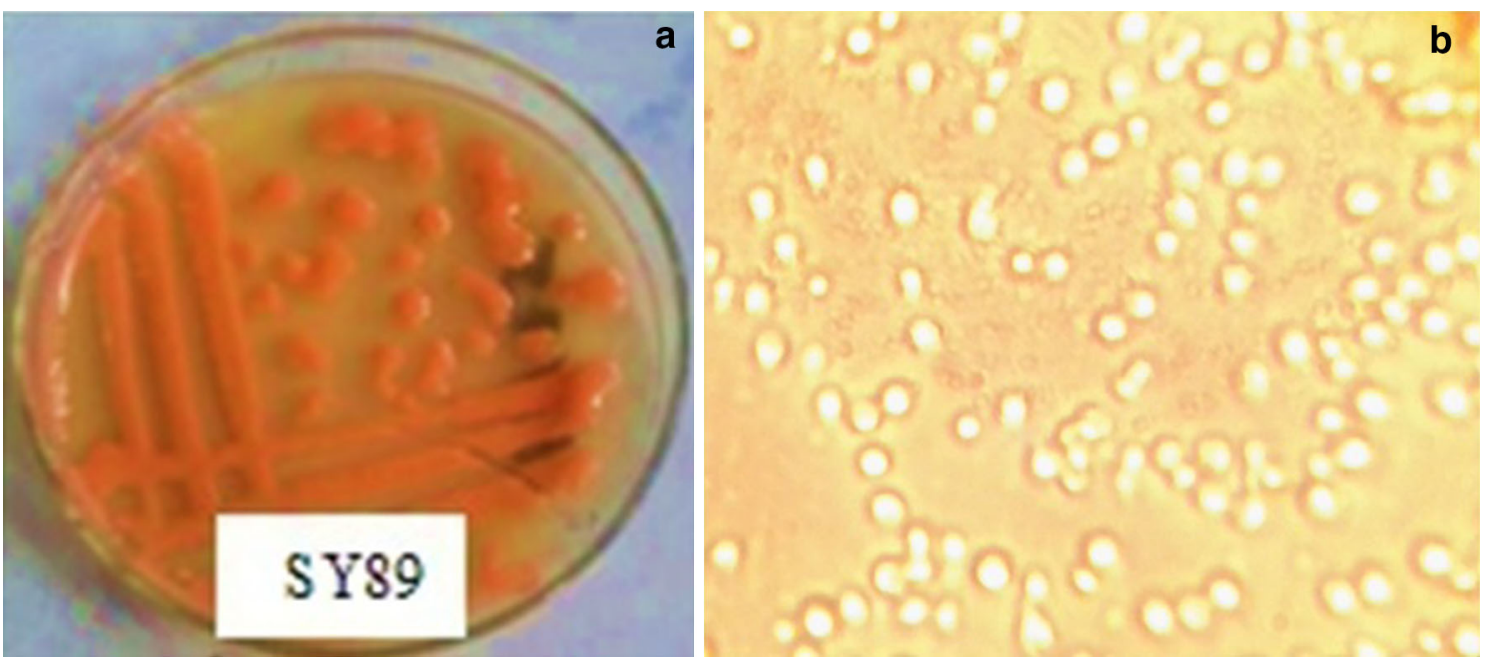

Fig. 1 a Colony morphology of SY89 and b budding SY89 cell

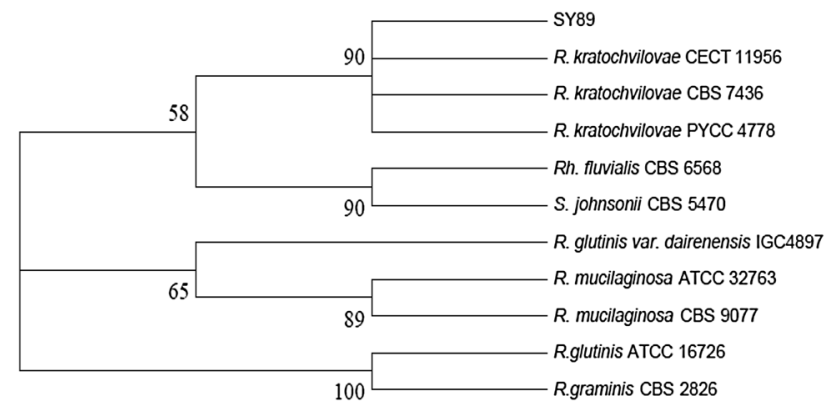

Fig. 2 Phylogenetic tree of the D1/D2 domain of 26S rRNA gene sequences of oleaginous yeast strain SY89 with related yeast species in NCBI database. The tree was constructed using the NeighborJoining method of MEGA 7 software. The optimal tree with the sum of branch length $=0.99011017$ is shown. Bootstrap values (1000 tree interactions) are indicated at the nodes

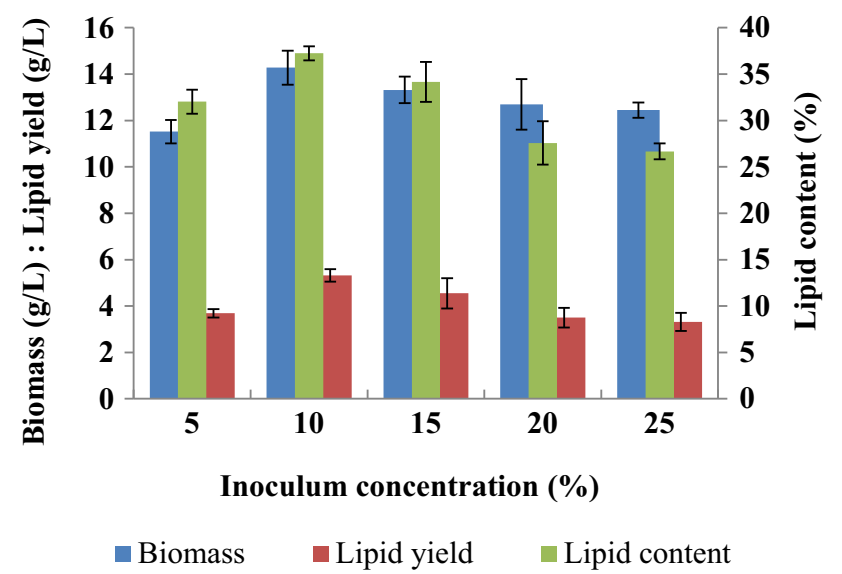

Fig. 3 Effect of inoculum size on yeast biomass production, lipid yield and cellular lipid content by SY89. Error bars in the figures represent standard deviation of $5 \% \mathrm{v} / \mathrm{v}$ was the optimum value for maximum biomass and lipid production by Cutaneotrichosporon cutaneum (syn, Trichosporon cutaneum) grown on corncob acid hydrolysate (Chen et al. 2013).

\section{Effect of carbon source}

Mamatha (2009) discussed that the biomass production, lipid accumulation and fatty acid profiles of oleaginous microorganisms are affected by the carbon source available during fermentation. In the current study, the effect of various carbon sources (glucose, sucrose, maltose, lactose, galactose, xylose, and glycerol) on biomass production, lipid yield and lipid content by SY89 was tested using nitrogen-limited media. Although considerable lipid yield and lipid content were attained by this yeast strain when grown on sucrose and maltose, SY89 gave the maximum biomass $(14.62 \pm 0.65 \mathrm{~g} / \mathrm{L})$, lipid yield $(6.53 \pm 0.34 \mathrm{~g} / \mathrm{L})$ and lipid content $(44.66 \pm 0.95 \%)$ when glucose was used as a carbon source (Fig. 4). The lowest biomass $(10.38 \pm 2.14 \mathrm{~g} / \mathrm{L})$, lipid yield $(2.70 \pm 0.04 \mathrm{~g} / \mathrm{L})$ and lipid content $(26.01 \pm 2.11 \%)$ was attained by SY89 when grown in media containing xylose as carbon source. This results lead to selection of glucose as a carbon source for further studies. This confirms the results obtained by other researchers that glucose is the preferred carbon source for lipid production by oleaginous yeasts (Patel et al. 2014; Ahmad et al. 2015; Enshaeieh et al. 2015).

\section{Effect of glucose concentration}

To determine the optimum glucose concentration for maximum biomass production, lipid yield and lipid content of SY89, various concentrations of glucose were tested in a 


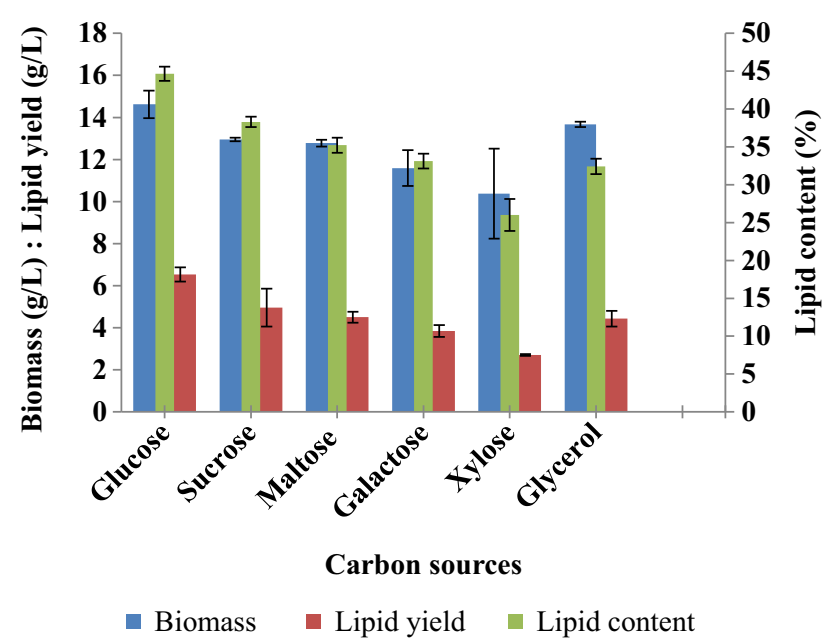

Fig. 4 Effect of different carbon sources on biomass production and lipid yield by SY89. Error bars in the figures represent standard deviation

nitrogen-limited media. A medium containing $50 \mathrm{~g} / \mathrm{L}$ of glucose was found to be optimum for maximum production of biomass $(16.37 \pm 1.57 \mathrm{~g} / \mathrm{L})$, lipid yield $(6.95 \pm 0.42 \mathrm{~g} /$ L) and lipid content $(42.46 \pm 2.31 \%)$ (Fig. 5). In contrast, the lowest biomass $(10.79 \pm 1.75 \mathrm{~g} / \mathrm{L})$, lipid yield $(2.24 \pm 0.25 \mathrm{~g} / \mathrm{L})$ and lipid content $(20.76 \pm 1.86 \%)$ were attained by this oleaginous yeast, when the medium contained $10 \mathrm{~g} / \mathrm{L}$ glucose (Fig. 5). These results lead to the selection of $50 \mathrm{~g} / \mathrm{L}$ glucose for further optimization.

\section{Effect of nitrogen source}

The effect of combined organic nitrogen (yeast extract, peptone and urea at $0.5 \mathrm{~g} / \mathrm{L}$ ) and inorganic nitrogen sources

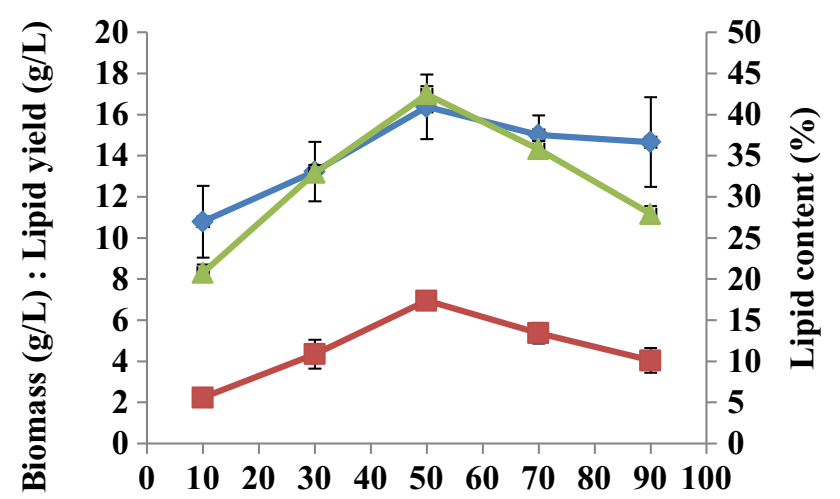

Glucose concentration $(\mathrm{g} / \mathrm{L})$

$\neg$ Biomass $\rightarrow$-Lipid yield $\rightarrow$ Lipid content

Fig. 5 Effect of various glucose concentrations on biomass production and lipid yield by SY89. Error bars in the figures represent standard deviation
$\left(\mathrm{NH}_{4}\right)_{2} \mathrm{SO}_{4}$ and $\mathrm{NH}_{4} \mathrm{Cl}$ at $0.30 \mathrm{~g} / \mathrm{L}$ by $\mathrm{SY} 89$ was determined in the nitrogen-limited media composed of $50 \mathrm{~g} / \mathrm{L}$. Maximum biomass of circa $16 \mathrm{~g} / \mathrm{L}$ was obtained when media containing combinations of $\left(\mathrm{NH}_{4}\right)_{2} \mathrm{SO}_{4}$ with yeast extract or $\left(\mathrm{NH}_{4}\right)_{2} \mathrm{SO}_{4}$ and peptone was used. In addition, this yeast provided the maximum lipid yield $(7.27 \pm 0.23 \mathrm{~g} / \mathrm{L})$ and lipid content $(42.89 \pm 2.05 \%)$ when $\left(\mathrm{NH}_{4}\right)_{2} \mathrm{SO}_{4}$ and yeast extract were used as nitrogen sources in combinations. The lowest biomass $(13.15 \pm 0.12 \mathrm{~g} / \mathrm{L})$, lipid yield $(3.78 \pm 0.67 \mathrm{~g} / \mathrm{L})$ and lipid content $(28.75 \pm 0.75 \%)$ were obtained when $\mathrm{NH}_{4} \mathrm{Cl}$ and urea were used in combination (Fig. 6). According to other researchers different nitrogen sources support different oleaginous yeasts either in combination or alone. For example, Zhu et al. (2008) grew Geotrichum (syn, Trichosporon) fermentans by varying different nitrogen sources [ $\left(\mathrm{NH}_{4}\right)_{2} \mathrm{SO}_{4}, \mathrm{NH}_{4} \mathrm{Cl}, \mathrm{NH}_{4} \mathrm{NO}_{3}$, peptone and urea)]. Among the nitrogen sources tested, urea supported maximum biomass. With respect to lipid content and lipid yield, peptone was the best nitrogen source. On the other hand, Kraisintu et al. (2010) reported that Rhodotorula (syn, Rhodosporidium) toruloidesDMKU3-TK16 produced the most biomass when the yeast was grown in medium containing yeast extract and $\left(\mathrm{NH}_{4}\right)_{2} \mathrm{SO}_{4}$ as nitrogen sources.

Based on the results in Fig. 6, lipid yield and lipid content percentage at different combinations of different nitrogen sources, it is evident that $\left(\mathrm{NH}_{4}\right)_{2} \mathrm{SO}_{4}$ and yeast extract are the optimum nitrogen sources for SY89. Accordingly, $\left(\mathrm{NH}_{4}\right)_{2} \mathrm{SO}_{4}$ and yeast extract were selected as the optimum nitrogen sources for SY89 for further optimization studies.

\section{Effect of $C / N$ ratio}

The $C / N$ ratio in the growth medium plays a pivotal role in achieving high lipid accumulation in oleaginous microorganisms. For the production of lipids by oleaginous

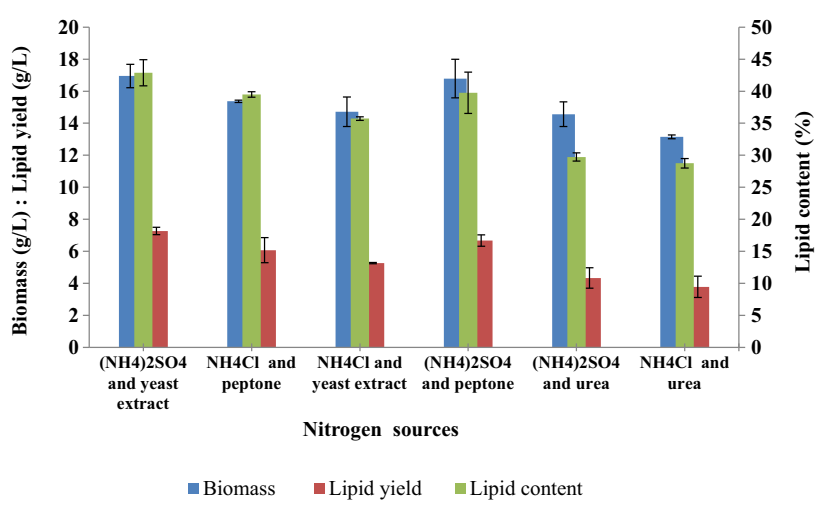

Fig. 6 Effect of different nitrogen sources on biomass production and lipid content in SY89. Error bars in the figures represent standard deviation 
microorganisms, there must be nutrient imbalance in the culture medium and specifically the $C / N$ ratio has to be high (Beopoulos et al. 2009). According to Papanikolaou and Aggelis (2011) $C / N$ ratio must be greater than 20. The optimal $C / N$ value has to not only to be high (e.g., in the range between 80 and $350 \mathrm{~mol} / \mathrm{mol}$ ), but also strongly depends on the oleaginous species, the medium composition, the carbon and nitrogen sources used (Ykema et al. 1986). In a media having high $C / N$ ratio, sufficient carbon will be left in the medium and be utilized for lipid accumulation during cell growth (Ratledge and Wynn 2002). To study the effect of $C / N$ ratio on biomass production, lipid yield and lipid content of SY89, varying $C / N$ ratios from 40 to 160 in nitrogen- limited media composed of $50 \mathrm{~g} / \mathrm{L}$ of glucose, $0.5 \mathrm{~g} / \mathrm{L}$ of yeast extract and various concentrations of $\left(\mathrm{NH}_{4}\right)_{2} \mathrm{SO}_{4}$ and adjusted $\mathrm{pH}$ of 5.5, were used (Table 1). The approximate total nitrogen content of yeast extract was found to be $20 \%$ according to the Kjeldahl method, used.

The maximum biomass $(12.89 \pm 1.37 \mathrm{~g} / \mathrm{L})$, lipid yield $(5.87 \pm 0.53 \mathrm{~g} / \mathrm{L})$ and lipid content $(42.54 \pm 3.32 \%)$ were observed at $\mathrm{C} / \mathrm{N}$ ratio of 120 (Fig. 7). At $C / N$ ratio of 40 , SY89 showed its minimum biomass, lipid yield and lipid content as $9.70 \pm 0.88 \mathrm{~g} / \mathrm{L}$, lipid yield $1.96 \pm 0.42 \mathrm{~g} / \mathrm{L}$ and $20.21 \pm 1.46 \%$, respectively (Fig. 7). Based on the above result, $\mathrm{C} / \mathrm{N}$ ratio of 120 was optimum and selected for further optimization studies. Other researchers also reported that $C / N$ ratio is an important factor for maximum lipid production and found an optimum $C / N$ ratio in which the yeasts they tested. For example, G. fermentans gave maximum lipid yield at $C / N$ ratio of 163 (Zhu et al. 2008). Maximum lipid content was attained by $R$. toruloides DMAKU3-TK16 at $C / N$ ratio of 140 (Kraisintu et al. 2010).

\section{Effect of $p H$}

$\mathrm{pH}$ is one of the significant physiological parameters affecting cell growth and lipid yield (Hong et al. 2006). To determine the optimum $\mathrm{pH}$ for maximum production of cell biomass, lipid yield and cellular lipid content in SY89, a nitrogen-limited media with $\mathrm{pH}$ ranging from 4.0 to 7.0 were

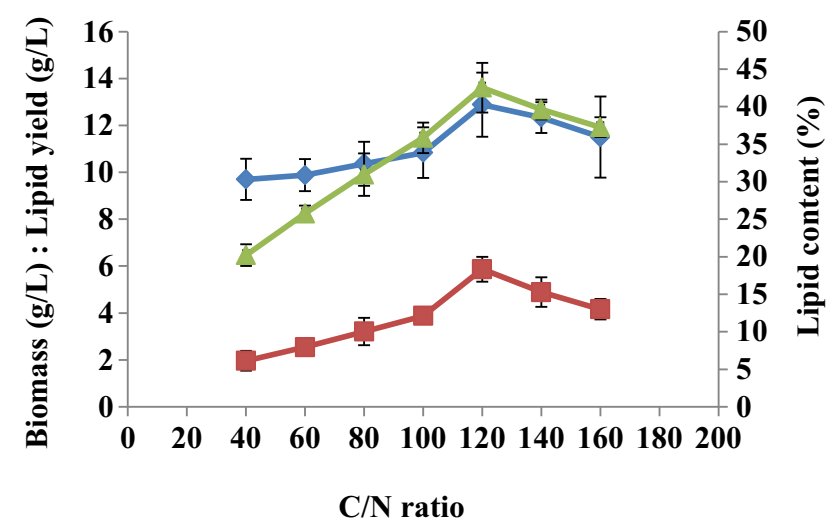

$\checkmark$ Biomass $\rightarrow$-Lipid yield $\rightarrow$ Lipid content

Fig. 7 Effect of $C / N$ ratio on biomass production, lipid yield and lipid content by SY89. Error bars in the figures represent standard deviation

evaluated (Fig. 8). Maximum biomass $(16.32 \pm 0.78 \mathrm{~g} / \mathrm{L})$ with cellular lipid yield of $6.28 \pm 0.03 \mathrm{~g} / \mathrm{L}$ and lipid content of $38.38 \pm 0.67 \%$ were achieved at $\mathrm{pH} 5.5$. At $\mathrm{pH} 7.0$, the yeast showed its lowest biomass, lipid yield and lipid content. Accordingly, $\mathrm{pH} 5.5$ was selected as the optimum $\mathrm{pH}$ for further optimization. This is similar to the results obtained for $R$. toruloides DMAKU3-TK16 (Kraisintu et al. 2010), Rhodotorula glutinis (Tao et al. 2008) and Cutaneotrichosporon curvatus (El-Fadaly et al. 2009).

\section{Effect of temperature}

Cellular lipid accumulation is critically affected by temperature of the culture medium. Temperature affects all living organisms and controls the growth rate, lipid synthesis and alters the composition of cellular fatty acids (Mamatha 2009). Biomass and lipid yield as well as intracellular lipid content of SY89 were tested by growing it at temperatures of 20, 25, 30, 35 and $40{ }^{\circ} \mathrm{C}$ in a culture with $10 \% \mathrm{v} / \mathrm{v}$ inoculum size in nitrogen-limited medium listed above. The $\mathrm{pH}$ was adjusted to 5.5. At a temperature of $30{ }^{\circ} \mathrm{C}, \mathrm{SY} 89$ produced maximum biomass $(15.06 \pm 1.03 \mathrm{~g} / \mathrm{L})$, lipid yield $(7.16 \pm 0.02 \mathrm{~g} / \mathrm{L})$ and lipid content (47.54 $\pm 1.34 \%$ ) (Fig. 9). These maximum
Table 1 The $C / N$ ratio in nitrogen- limited medium

\begin{tabular}{lll}
\hline$C / N$ ratio & $\begin{array}{l}\text { Carbon source } \\
(\mathrm{glucose})(\mathrm{g} / \mathrm{L})\end{array}$ & Nitrogen sources \\
\hline 40 & 50 & $0.5 \mathrm{~g} / \mathrm{L}$ yeast extract and $1.89 \mathrm{~g} / \mathrm{L}\left(\mathrm{NH}_{4}\right)_{2} \mathrm{SO}_{4}$ \\
60 & 50 & $0.5 \mathrm{~g} / \mathrm{L}$ yeast extract and $1.08 \mathrm{~g} / \mathrm{L}\left(\mathrm{NH}_{4}\right)_{2} \mathrm{SO}_{4}$ \\
80 & 50 & $0.5 \mathrm{~g} / \mathrm{L}$ yeast extract and $0.71 \mathrm{~g} / \mathrm{L}\left(\mathrm{NH}_{4}\right)_{2} \mathrm{SO}_{4}$ \\
100 & 50 & $0.5 \mathrm{~g} / \mathrm{L}$ yeast extract and $0.47 \mathrm{~g} / \mathrm{L}\left(\mathrm{NH}_{4}\right)_{2} \mathrm{SO}_{4}$ \\
120 & 50 & $0.5 \mathrm{~g} / \mathrm{L}$ yeast extract and $0.31 \mathrm{~g} / \mathrm{L}\left(\mathrm{NH}_{4}\right)_{2} \mathrm{SO}_{4}$ \\
140 & 50 & $0.5 \mathrm{~g} / \mathrm{L}$ yeast extract and $0.20 \mathrm{~g} / \mathrm{L}\left(\mathrm{NH}_{4}\right)_{2} \mathrm{SO}_{4}$ \\
160 & 50 & $0.5 \mathrm{~g} / \mathrm{L}$ yeast extract and $0.12 \mathrm{~g} / \mathrm{L}\left(\mathrm{NH}_{4}\right)_{2} \mathrm{SO}_{4}$ \\
\hline
\end{tabular}




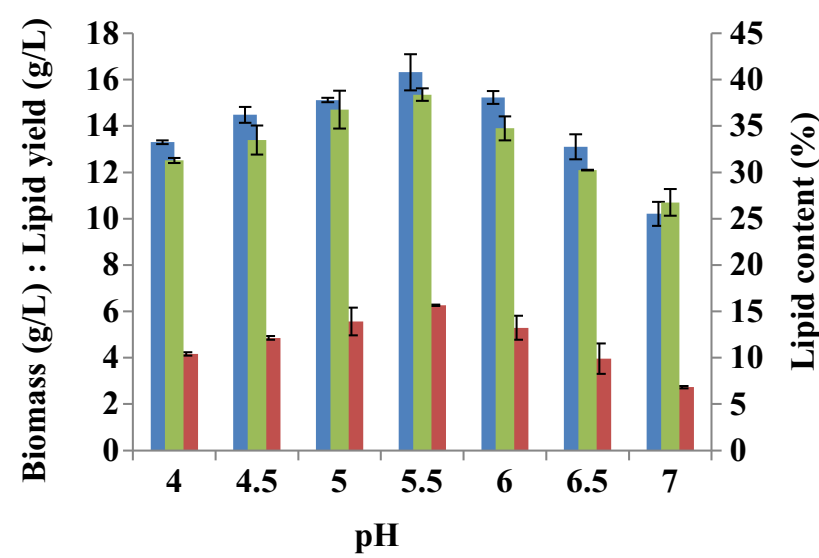

Biomass $\quad$ Lipid yield $\quad$ Lipid content

Fig. 8 Effect of pH on biomass production and lipid yield by SY89. Error bars in the figures represent standard deviation

values achieved at $30{ }^{\circ} \mathrm{C}$ are in agreement with results of other authors (Syed et al. 2006; Mamatha 2009). This temperature was selected for further experiments.

\section{Effect of agitation rate and culture volume}

It is suggested that oleaginous yeasts require substantial oxygen supply for energy and biosynthesis (Hong et al. 2006; Saad et al. 2014). One factor that influences the oxygen levels in medium is agitation rate. By increasing agitation rate, the dissolved oxygen in the medium increases, which enhances growth and lipid content (Enshaeieh et al. 2013). The effect of agitation rate on cell biomass production, lipid yield and lipid content by SY89 was determined under nitrogen-limited conditions by varying the agitation speed from 100 to $225 \mathrm{rpm}$. Maximum biomass of $14.25 \pm 0.75 \mathrm{~g} / \mathrm{L}$ was attained by SY 89 when the agitation rate was held at $175 \mathrm{rpm}$
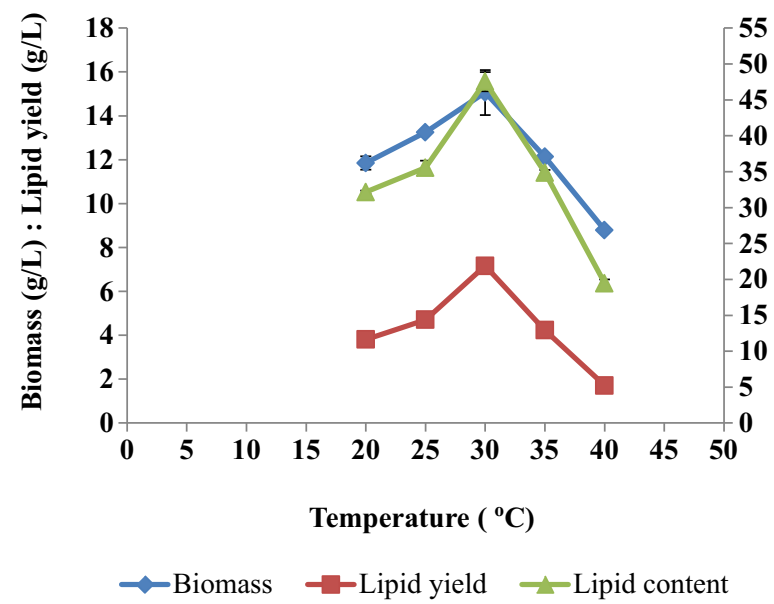

Fig. 9 Effect of temperature on biomass production and lipid yield by SY89. Error bars in the figures represent standard deviation
(Fig. 10), while the highest lipid yield $(6.24 \pm 0.66 \mathrm{~g} / \mathrm{L})$ and lipid content $(46.37 \pm 2.36 \%)$ were obtained by this oleaginous yeast strain when the agitation speed was held at $225 \mathrm{rpm}$. Other researchers also investigated the optimum agitation rate for different oleaginous yeasts. For example, optimum agitation rate for production of single cell oil by $R$. glutinis was $180 \mathrm{rpm}$ (Dai et al. 2007). El-Fadaly et al. (2009) investigated the effect of agitation speed on the SCO production by $C$. curvatus NRRLY-1511 and found that maximum cell dry cell mass and lipid yield were obtained at $200 \mathrm{rpm}$. Based on the above observation, all further experiments were carried out in nitrogen-limited media agitation at $225 \mathrm{rpm}$ for SY89.

The culture volume also influences the oxygen level in the medium. In this study, the effect of culture volume on biomass production, lipid yield and cellular lipid content by SY89, the submerged cultures were performed by changing the ratio $(R)$ of volume of the medium to the total volume of the flask $(250 \mathrm{~mL})$. The ratios used were $0.1,0.2,0.3,0.4$, and 0.5 . The flasks were kept at $30{ }^{\circ} \mathrm{C}$ with agitation speed of $200 \mathrm{rpm}$ for $144 \mathrm{~h}$. In this investigation maximum biomass $(15.22 \pm 0.34 \mathrm{~g} / \mathrm{L})$, lipid yield $(6.47 \pm 0.08 \mathrm{~g} / \mathrm{L})$ and lipid content $(42.51 \pm 1.43 \%)$ were exhibited when the ratio of volume of media to the volume of the flask was held at 0.2. As shown in Fig. 11, there is a decrease in biomass, lipid yield and lipid content as the volume of the culture medium increased. This study confirms results obtained by Hong et al. (2006) and Mamatha (2009).

\section{Effect of incubation period}

Different oleaginous microorganisms require different incubation period for maximum biomass production and lipid accumulation. In this investigation, the effect of

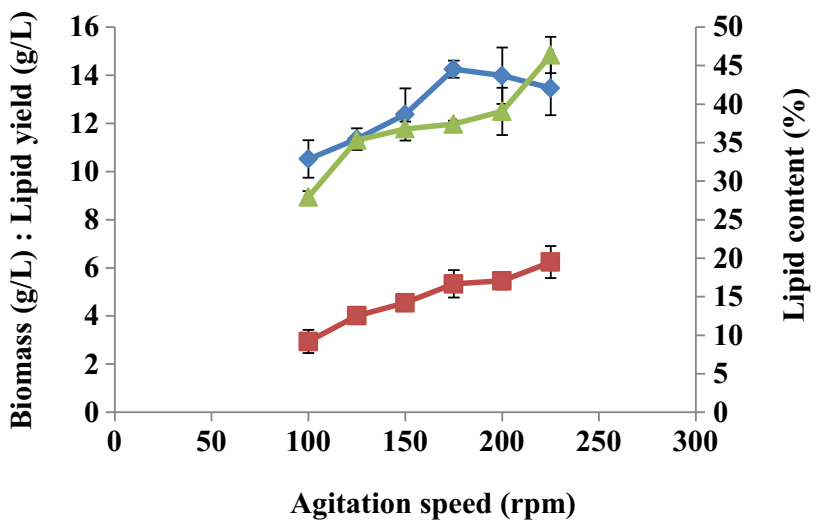

$$
\neg \text { Biomass } \quad-\text { Lipid yield } \quad-\text { Lipid content }
$$

Fig. 10 Effect of agitation speed on biomass production, lipid yield and lipid content by SY89. Error bars in the figures represent standard deviation 


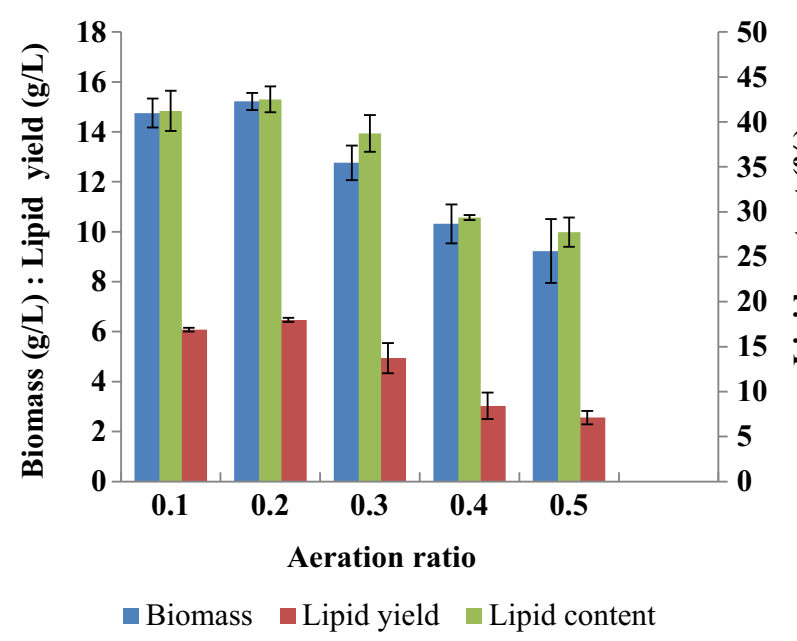

Fig. 11 Effect of aeration ratio based on culture volume on biomass production, lipid yield and cellular lipid content of SY89

incubation period on biomass production, lipid yield and intracellular lipid content by SY89 was determined by growing the yeast $0,24,48,72,96,120,144$ and $168 \mathrm{~h}$ in nitrogen-limited media. SY89 gave maximum biomass $(16.08 \pm 0.78 \mathrm{~g} / \mathrm{L})$ at the end of 168 -h incubation. However, this yeast gave maximum lipid yield $(7.65 \pm 0.77 \mathrm{~g} /$ $\mathrm{L})$ and lipid content $(51.17 \pm 1.72 \%)$ after growth period of 144-h (Fig. 12). A decrease in lipid yield and lipid content were exhibited by this oleaginous yeast after the 144-h growth. Based on the above observations, all such further experiments were carried out by incubating this oleaginous yeast for 144-h. Other researchers also reported different optimum incubation periods for maximum production of lipid by different oleaginous yeasts (Hong et al. 2006; Dai et al. 2007; El-Fadaly et al. 2009; Kraisintu et al. 2010).
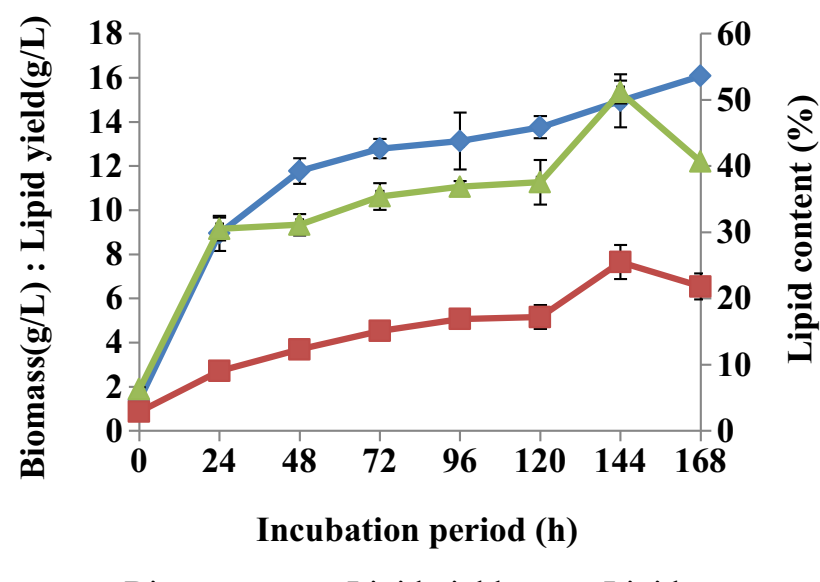

$\sim$ Biomass $\rightarrow$-Lipid yield $\rightarrow$ Lipid content

Fig. 12 Time course of biomass, lipid production and cellular lipid content by SY89. Error bars in the figures represent standard deviation

\section{Bioreactor cultivation SY89 under the optimized conditions}

R. kratochvilovae SY89 was grown on nitrogen-limited medium using glucose as carbon source for $144 \mathrm{~h}$. The fermentation was undertaken in a $0.8 \mathrm{~L}$ stirred-tank batch bioreactor. Set-up of the fermentation process is shown in Fig. 13. The results obtained in this study were considerable and showed high potential of biomass production, lipid yield and lipid content by $R$. kratochvilovae SY89. Under all the optimized conditions, the yeast gave maximum biomass $(15.34 \pm 1.47 \mathrm{~g} / \mathrm{L}), \quad$ lipid yield $(8.60 \pm 0.81 \mathrm{~g} / \mathrm{L})$ and lipid content $(56.06 \pm 1.70 \%)$.

\section{Fatty acid composition}

The type of species and growth conditions, i.e., temperature, $\mathrm{pH}$, type of substrate, variation in $\mathrm{C} / \mathrm{N}$ ratio and oxygen not only influence the efficiency of lipid accumulation, but also the fatty acid profiles of the cellular lipids (Jacob 1993). The fatty acid composition of lipids produced by SY89 is provided in Table 2. The total lipids of this yeast contained mostly oleic acid (C18:1) (53.82 $\pm 1.25 \%)$, followed by palmitic (C16:0) $(18.63 \pm 0.53 \%)$, linoleic (C18:2) $(13.34 \pm 1.15 \%)$, stearic $(\mathrm{C} 18: 0)(5.68 \pm 0.32 \%)$, linolenic $(\mathrm{C} 18: 3) \quad(5.47 \pm 0.60 \%)$ and palmitoleic (C16:1) $(0.50 \pm 0.09 \%)$ acids. Similar results on major fatty acid profiles of different oleaginous yeasts were reported by other researchers (Ahmad et al. 2015). The fatty acid profiles that were exhibited by SY89 were not only similar to fatty acid profiles of other oleaginous yeasts, but also they are similar

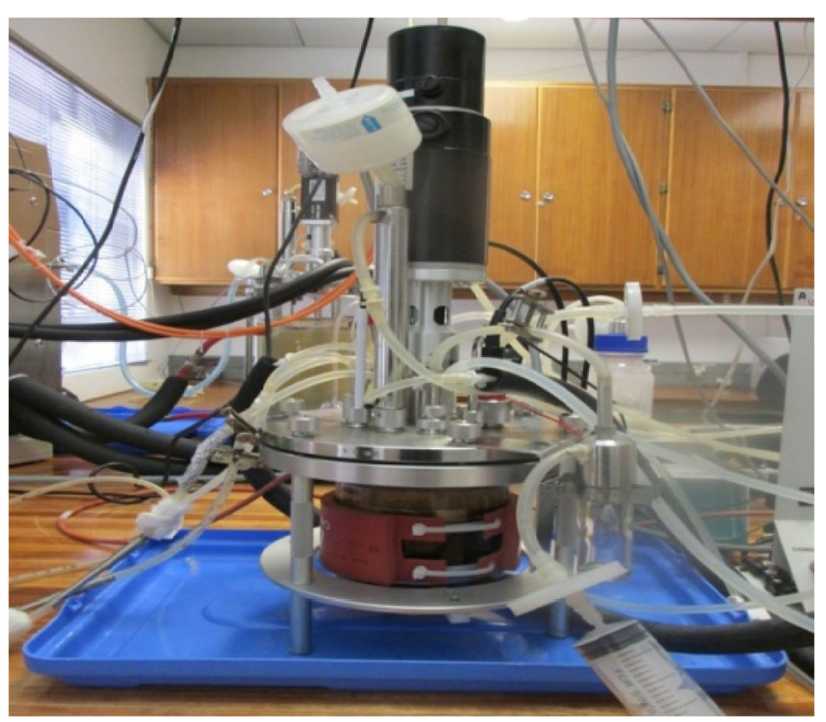

Fig. 13 Experimental set-up during bioreactor cultivation of $R$. kratochvilovae SY89. Cultivation parameters such as $\mathrm{pH}$, temperature, dissolved oxygen, foam formation, stirring speed, etc., were controlled using computer system 
Table 2 Comparison of fatty acid profiles of SY89 with oils of other oleaginous yeasts and selected vegetable oils

\begin{tabular}{|c|c|c|c|c|c|c|c|}
\hline Fatty acid & SY89 & C. albidus & $\begin{array}{l}\text { R. mucilaginosa } \\
\text { TJY15a }\end{array}$ & $\begin{array}{l}\text { R. toruloides } \\
\text { DMKU3-TK16 }\end{array}$ & Soybean & Palm & Sunflower \\
\hline \multicolumn{8}{|c|}{ Relative abundance of fatty acid residues (\%w/w) } \\
\hline C14:0 & - & $1.5 \pm 0.6$ & $1.5 \pm 0.1$ & 0.96 & - & - & - \\
\hline $\mathrm{C} 16: 0$ & $18.63 \pm 0.53$ & $22.7 \pm 0.1$ & $22.3 \pm 0.4$ & 22.49 & 12 & 43 & 6 \\
\hline $\mathrm{C} 16: 1$ & $0.50 \pm 0.09$ & $1.7 \pm 0.4$ & $1.8 \pm 0.1$ & 0.82 & - & - & - \\
\hline $\mathrm{C} 18: 0$ & $5.68 \pm 0.32$ & $4.1 \pm 1.3$ & $5.2 \pm 0.5$ & 14.56 & 3 & 5 & 3 \\
\hline $\mathrm{C} 18: 1$ & $53.82 \pm 1.25$ & $34.1 \pm 2.5$ & $63.5 \pm 1.8$ & 41.54 & 23 & 41 & 17 \\
\hline C18:2 & $13.34 \pm 1.15$ & $35.8 \pm 2.2$ & $5.7 \pm 0.2$ & 15.12 & 56 & 10 & 74 \\
\hline $\mathrm{C} 18: 3$ & $5.47 \pm 0.60$ & - & - & 4.51 & 6 & - & - \\
\hline Reference & This work & $\begin{array}{c}\text { Ahmad et al. } \\
\text { (2015) }\end{array}$ & Li et al. (2010) & Kraisintu et al. (2010) & $\begin{array}{l}\text { Ma and Hanna } \\
\text { (1999) }\end{array}$ & $\begin{array}{l}\text { Ma and Hanna } \\
\text { (1999) }\end{array}$ & $\begin{array}{l}\text { Ma and Hanna } \\
\text { (1999) }\end{array}$ \\
\hline
\end{tabular}

Values for relative abundance of fatty acid residues for SY89 are expressed as mean \pm SD

to the fatty acid profiles of different vegetable oils (Table 2). The cellular lipids contain circa 70\% C16:0 and C18:1, suggesting that this strain could be used as feedstock for biodiesel production (Byreddy et al. 2015).

\section{Conclusions}

In this study it was observed that cultivation conditions had an influence on lipid accumulation of SY89. Comparing it to previous data it is clear that there are some differences across species and strains and it is, therefore, important to investigate the optimal parameters for each strain tested. Under the optimized conditions, SY89 yeast gave lipid content of $56.06 \pm 1.70 \%$ of the biomass $(15.34 \pm 1.47 \mathrm{~g} /$ L). Such values suggest that SY89 could be considered as an attractive yeast for the production of lipid if cultivated under fed-batch or continuous bioreactor. Furthermore, the concentration of saturated and monounsaturated fatty acids of SY89 adds up $78.63 \pm 2.19 \%$. This suggests that this strain could be used as a feedstock for biodiesel production.

Acknowledgements Tamene is thankful to Ethiopian Ministry of Science and Technology for their financial support.

\section{Compliance with ethical standards}

Conflicts of interests The authors declare that they have no conflicts of interests.

\section{References}

Ahmad FB, Zhang Z, Doherty WOS, O'Hara IM (2015) A multicriteria analysis approach for ranking and selection of microorganisms for the production of oils for biodiesel production. Bioresour Technol 190:264-273

Amaretti A, Raimondi S, Sala M, Roncaglia L, Lucia MD, Leonardi A, Rossi M (2010) Single cell oils of the cold adapted oleaginous yeast Rhodotorula glacialis DBVPG4875. Microb Cell Fact 9:73
Angerbauer C, Siebenhofer M, Mittelbach M, Guebitz GM (2008) Conversion of sewage sludge into lipids by Lipomyces starkeyi for biodiesel production. Bioresour Technol 99:3051-3056

Bandaiphet C, Prasertsan P (2006) Effect of aeration and agitation rates and scale-up on oxygen transfer coefficient, $\mathrm{kLa}$ in exopolysaccharide production from Enterobacter cloacae WD7. Carbohyd Polym 66:216-228

Beopoulos A, Mrozova Z, Thevenieau F, Dall MT, Hapala I, Papanikolaou S, Chardot T, Nicaud JM (2008) Control of lipid accumulation in the yeast Yarrowia lipolytica. Appl Environ Microbiol 74:7779-7789

Beopoulos A, Chardot T, Nicaud JM (2009) Yarrowia lipolytica: a model and a tool to understand the mechanisms implicated in lipid accumulation. Biochimie 91:692-696

Butte W (1983) Rapid method for the determination of fatty acid profiles from fats and oils using trimethylsulphonium hydroxide for transesterification. J Chromatogr A 261:142-145

Byreddy AR, Gupta A, Barrow CJ, Puri M (2015) Comparison of cell disruption methods for improving lipid extraction from Thraustochytrid strains. Mar Drugs 13:5111-5127

Chen XF, Huang C, Yang XY, Xiong L, Chen XD, Ma LL (2013) Evaluating the effect of medium composition and fermentation condition on the microbial oil production by Trichosporon cutaneum on corncob acid hydrolysate. Bioresour Technol $143: 18-24$

Dai C, Tao J, Xie F, Dai Y, Zhao M (2007) Biodiesel generation from oleaginous yeast Rhodotorula glutinis with xylose assimilating capacity. Afr J Biotechnol 6:2130-2134

de Hoog GS, Gerrits van den Ende AHG (1998) Molecular diagnostics of clinical strains of filamentous basidiomycetes. Mycoses 41:183-189

Economou CN, Aggelis G, Pavlou S, Vayenas DV (2011) Modeling of single cell oil production under nitrogen-limited and substrate inhibition condition. Biotechnol Bioeng 108:1049-1055

El-Fadaly HA, El-Naggar NA, Marwan SM (2009) Single cell oil production by an oleaginous yeast strain in a low cultivation medium. Res J Microbiol 4:301-313

Enshaeieh M, Abdoli A, Nahvi I (2013) Medium optimization for biotechnological production of single cell oil using Yarrowia lipolytica M7 and Candida sp. J Cell Mol Res 5:17-23

Enshaeieh M, Abdoli A, Madani M (2015) Single cell oil (SCO) production by Rhodotorula mucilaginosa and its environmental benefits. J Agr Sci Tech 17:387-400

Folch J, Lees M, Sloane-Stanley GH (1957) A simple method for the isolation and purification of total lipids from animal tissues. J Biol Chem 226:497-509 
Hong LY, Bo L, Bao ZZ, Wu BF (2006) Optimization of culture conditions for lipid production by Rhodosporidium toruloides. Chin J Biotech 22:650-656

Jacob Z (1993) Yeast lipid biotechnology. Adv Appl Microbiol $39: 185-212$

Jiru TM, Abate D, Kiggundu N, Pohl C, Groenewald M (2016) Oleaginous yeasts from Ethiopia. AMB Exp 6:78

Kitcha S (2012) Screening of oleaginous yeasts and optimization for lipid production using crude glycerol as a carbon source, thesis submitted to the Prince of Songkla University for the award of degree of doctor of philosophy in biotechnology, pp 1-162

Knutsen AK, Robert V, Poot GA, Figge M, Epping W, Holst-Jensen A, Skaar I, Smith MT (2007) Polyphasic re-examination of Yarrowia lipolytica strains and the description of three novel Candida species: Candida osloensis sp.nov, Candida alimentaria sp nov and Candida hollandica sp nov. Int J Syst Evol Microbiol 57:2426-2435

Kraisintu P, Yongmanitchai W, Limtong S (2010) Selection and optimization for lipid production of a newly isolated oleaginous yeast, Rhodosporidium toruloides DMKU3-TK16. Kasetsart J (Nat Sci) 44:436-445

Krishna G, Ranjhan SK (1980) Laboratory manual for nutrition research. Vicas Publishing House, New Delhi, pp 1-134

Kumar S, Stecher G, Tamura K (2016) MEGA7: molecular evolutionary genetics analysis version 7.0 for bigger datasets. Mol Biol Evol 33:1870-1874

Kurtzman CP, Fell JW, Boekhout T, Robert V (2011) Methods for isolation, phenotypic characterization and maintenance of yeasts. In: Kurtzman CP, Fell JW, Boekhout T (eds) The yeasts: a taxonomic study, 5th edn. Elsevier Science, Amsterdam, pp 87-110

Li Q, Du W, Liu D (2008) Perspectives of microbial oils for biodiesel production. Appl Microbiol Biotechnol 80:749-756

Li M, Liu GM, Chi Z, Chi ZM (2010) Single cell oil production from hydrolysate of cassava starch by marine-derived yeast Rhodotorula mucilaginosa TJY15a. Biomass Bioenerg 34:101-107

Luque R, Lovett JC, Datta B, Clancy J, Campelo JM, Romero AA (2010) Biodiesel as feasible petrol fuel replacement: a multidisciplinary overview. Energ Enivron Sci 3:1706-1721

Ma F, Hanna MA (1999) Biodiesel production: a review. Bioresour Technol 70:1-15

Mamatha SS (2009) Polyunsaturated fatty acids of Mucor sp. with special reference to gamma linolenic acid, thesis submitted to the University of Mysore for the award of degree of doctor of philosophy in microbiology, pp 123-169

Pan LX, Yang DF, Shao L, Chen WGG, Liang ZQ (2009) Isolation of the oleaginous yeasts from the soil and studies of their lipid producing capacities. Food Technol Biotechnol 47:215-220

Papanikolaou S, Aggelis G (2011) Lipids of oleaginous yeasts. Part II: technology and potential applications: a review. Eur J Lipid Sci Technol 113:1052-1073
Patel A, Pravez M, Deeba F, Pruthi V, Singh RP, Pruthi PA (2014) Boosting accumulation of neutral lipids in Rhodosporidium kratochvilovae HIMPA1 grown on hemp (Cannabis sativa Linn) seed aqueous extract as feedstock for biodiesel production. Bioresour Technol 165:214-222

Ratledge C, Wynn JP (2002) The biochemistry and molecular biology of lipid accumulation in oleaginous microorganisms. Adv Appl Microbiol 51:1-51

Saad N, Abdeshahian P, Kalil MS, Yusoff WMW, Hamid AA (2014) Optimization of aeration and agitation rate for lipid and gamma linolenic acid production by Cunninghamella bainieri 2a1 in submerged fermentation using response surface methodology. Sci World J 2014:12. doi:10.1155/2014/280146

Saxena RK, Anand P, Saran S, Isar J (2009) Microbial production of 1,3-propanediol: recent developments and emerging opportunities. Biotechnol Adv 27:895-913

Sha Q (2013) A comparative study on four oleaginous yeasts on their lipid accumulating capacity. Swedish University of Agricultural Sciences, Department of Microbiology, Master's thesis, pp 1-29

Syed MA, Singh SK, Pandey A, Kanjilal S, Prasad RBN (2006) Effects of various process parameters on the production of $\alpha$ Linolenic acid in submerged fermentation. Food Technol Biotechnol 44:282-287

Tao J, Dai C, Li R, Chen J, Zhang B (2008) The changes of microdiesel composition with the culture conditions by fallen leaves of Populus euramevicana cv. Int J Sustain Energ 27:73-79

Thakur MS, Prapulla SG, Karanth NG (1988) Microscopic observation of Sudan Black B staining to monitor lipid production by microbes. J Chem Technol Biotechnol 42:129-134

Vilgalys R, Hester M (1990) Rapid genetic identification and mapping of enzymatically amplified ribosomal DNA from several Cryptococcus species. J Bacteriol 172:4238-4246

Wang QM, Yurkov AM, Göker M, Lumbsch HT, Leavitt SD, Groenewald M, Theelen B, Liu XZ, Boekhout T, Bai FY (2015) Phylogenetic classification of yeasts and related taxa within Pucciniomycotina. Stud Mycol 81:149-189

White TJ, Bruns T, Lee S, Taylor J (1990) Amplification and direct sequencing of fungal ribosomal RNA genes for phylogenetics. In: Innis N, Gelfand D, Sninsky J, White T (eds) PCR protocols: a guide to methods and applications. Academic Press, New York, pp 315-332

Wu S, Zhao X, Shen H, Wang Q, Zhao ZK (2011) Microbial lipid production by Rhodosporidium toruloides under sulfate-limited conditions. Bioresour Technol 102:1803-1807

Ykema A, Verbree EC, Verseveld HW, Smit H (1986) Mathematical modeling lipid production by oleaginous yeasts in continuous cultures. Antonie Van Leeuwenhoek 52:491-506

Zhu LY, Zong MH, Wu H (2008) Efficient lipid production with Trichosporon fermentans and its use for biodiesel preparation. Bioresour Technol 99:7881-7885 